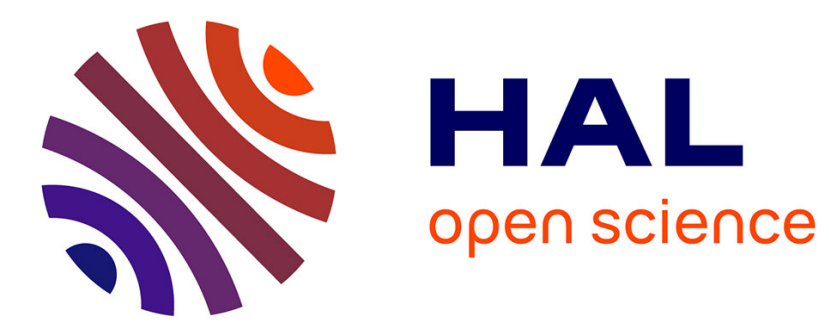

\title{
Adaptive Configuration of the Organization in Manufacturing Startup Companies
}

\author{
Christina Reuter, Bartholomäus Wolff, Pia Walendzik
}

\section{To cite this version:}

Christina Reuter, Bartholomäus Wolff, Pia Walendzik. Adaptive Configuration of the Organization in Manufacturing Startup Companies. IFIP International Conference on Advances in Production Management Systems (APMS), Sep 2016, Iguassu Falls, Brazil. pp.264-271, 10.1007/978-3-319-51133-

7_32.hal-01615734

\author{
HAL Id: hal-01615734 \\ https://hal.inria.fr/hal-01615734
}

Submitted on 12 Oct 2017

HAL is a multi-disciplinary open access archive for the deposit and dissemination of scientific research documents, whether they are published or not. The documents may come from teaching and research institutions in France or abroad, or from public or private research centers.
L'archive ouverte pluridisciplinaire HAL, est destinée au dépôt et à la diffusion de documents scientifiques de niveau recherche, publiés ou non, émanant des établissements d'enseignement et de recherche français ou étrangers, des laboratoires publics ou privés.

\section{(c)(1)}

Distributed under a Creative Commons Attribution| 4.0 International License 


\title{
Adaptive Configuration of the Organization in Manufacturing Startup Companies
}

\author{
Christina Reuter, Bartholomäus Wolff, and Pia Walendzik \\ RWTH Aachen University, Aachen, Germany \\ \{c.reuter, b.wolff, p.walendzik\}@wzl.rwth-aachen.de
}

\begin{abstract}
This paper presents an approach for manufacturing startup companies to reconfigure their organization and processes as a consequence of changing preconditions. Startup companies can be agile and adapt their organization continuously towards their preconditions and given resources better than established companies. The presented approach comprises three main levers for the configuration: process standardization, form of organization and the strategy for growth. Within the three dimensions the configuration can be done between process effectiveness or efficiency, between organization with specialists or generalist and between fast growth or sustainability in the organization.
\end{abstract}

Keywords: Process management. Organization. Organizational change.

\section{Challenges in the Set-up of Manufacturing Startup Companies}

In recent years companies face the challenge of designing more innovative products in less time to stay competitive. The number of product or business innovations has increased and companies are trying to provide an environment which is favorable for innovation and flexibility. Nevertheless some of the organizational structures of the companies don't fit with the new products or business innovations. Especially the organization's values and organization's processes need to fit with the innovation. As shown in Figure 1, there are different opportunities to handle those misfits. If a fit, both with the values and processes of an organization, isn't possible, the solution needs to be a separate team in a spin-off organization with new structures and processes [1]. The example of Audi AG proves this idea. In 2013 the Audi Business Innovation GmbH was established as a spin-off of the Audi AG. The objective of this spin-off is the implementation of interdisciplinary work and flexible working methods to develop products in the field of future mobility and digitisation complements. The highly interdisciplinary work to enable innovations in shorter cycles was not possible within the structures of an established company [2].

Besides spin-off organizations there are more and more startup companies which focus on innovative product or business ideas. Spin-off and startup companies start without any given organizations. They need to build-up new organizational structures and processes. If the company focus is set on manufacturing 




Fig. 1. Integration of innovative ideas in organization (Source: Adapted from [1])

processes compared to IT based innovation, the company needs more organizational structure directly from the beginning as there are usually more people involved. Manufacturing companies consist of different departments such as the production and manufacturing itself and several surrounding needed functions, e.g. purchasing, sales, material management, quality management, etc. Therefore structures and processes from startups developing software, where many examples can be found, can't be easily transferred. In 2011 IT based startup companies tried to focus on a new approach of developing software. Therefore software developers created a manifesto for agile software development. The Manifesto for Agile Software Development consists of four main principles [3]:

- Individuals and interactions over processes and tools

- Working software over comprehensive documentation

- Customer collaboration over contract negotiation

- Responding to change over following a plan

Today besides software developing startup companies more and more manufacturing companies are trying to implement these principles within their product development processes to react more flexible towards changes. The challenge is to adapt the principles, such as interactions over processes and tools, as well in their organizations to be more agile within their organizational structures.

\section{Deficiencies in the Set-up of Organizational Structure and Processes}

In the startup phase manufacturing companies are identifying which organization and process suits. After the initial phase of orientation, there is a risk that the impression is created that more organizational structures and process standardizations are needed. Therefore companies try to implement structures comparable to those of large companies which don't fit their needs and will slow 
down their innovation process and loose agility. On the one hand the initial organizational design is important on the other hand the organizational change. Therefore the corporate structures and business processes are explained in the following as the main elements which changes the configuration of the organization. The organization development explains in general the growth of a company.

\subsection{Business Process Management}

Business Process Management's purpose is to enable strategic alignment with the business goals and processes [4]. Within business process management there are several concepts and approaches towards that goal. The most relevant for this approach are the concepts of business process improvement, process innovation [5] or business process reengineering [6].

Business process reengineering, introduced in the 1990s by Hammer and Champy focusses on a radical strategic change in the organization. In contrast to incremental improvement in the optimization of single processes, business process reengineering considers a change in the holistic structure of a company: the business strategy, organization structure, culture and its processes. The different approaches towards business process reengineering have in common that they try to achieve a more efficient organization by running through the steps of mobilization, continued with the diagnosis, the redesign and ends with the transition [6]. The other named process management concepts are based on similar phases.

The concept of business process reengineering has been criticized as companies disregard the experience and expertise of their employees during the change process. Business process reengineering doesn't focus on people and their learning process but only on the process efficiency. In practical use many projects fail in the planning phase as the middle management is working against a structural change [7]. The concept of business process reengineering is lacking flexibility for startup companies. To be more agile, startup companies need to run through the phases several time in shorter cycles.

\subsection{Corporate Structure}

The corporate structure consists of several elements, such as the organizational structure and procedures, resources, the information system and communication management as well as the corporate culture. The organizational structure and information and communication system will be explained in the following as they are most relevant for the approach [8].

There are different types of organizational structures, such as functional, process or matrix organization. A functionally structured company is set-up with different department responsible for one task and competence each. Process oriented company focus on their business processes. A process organization focusses on the realization of process objectives and their optimization. The matrix organization tries to use economies of scale of the functional organization combined 
with the process focus on a special product or business unit. Employees in a matrix organization are working on two objectives from different leaders [9].

The information system deals with the supply of all needed information for the employees to fulfill their tasks. Information is usually connected between each other and can be linked between different systems [5].

The communication system is closely linked to the information system. It covers the infrastructure to share the information. This can be technical equipment, reporting lines or different boards. New ways of combining information and communication are interactive management systems. Interactive management systems combine the process of creating and sharing information, as each employee can access those systems easily and renew information in a defined workflow [10].

Each of the presented categories of the organization structure needs to be considered when designing new organizations. Especially the different types of organization structures do not fit the needs of startup companies. During the growth the requirements towards the organization are changing so that neither one nor the other approach fits the whole time. The challenge for startup companies is the transformation from one organizational structure to another.

\section{$2.3 \quad$ Organization Development}

Organization Development is the reaction of an organization towards external changes. It comprises the strategic planning and implementation of organizational changes including the behavior modification to improve the organization. The objective of organization development is to increase employees' level of satisfaction and commitment, increase cooperation and collaboration abilities among the employees and to increase the organization's problem solving [11].

The change process in the organizational development can be described in three phases by Lewin [12]. Organizational stability is maintained when there is a balance of two sets of forces acting upon the organization. The driving forces pushing on the organization to move in a new direction, whereas the restraining forces are hindering the movement. Therefore the first phase is about introducing a change by leaders to unfreeze the status quo. In the second phase leaders introduce the change by creating a possibility for movement towards the change vision. In the third phase the change gets stabilized by refreezing.

The approach by Lewin describes a process which should be done frequently in short cycles by startup companies to adapt to the given preconditions anytime.

In conclusion it can be said, that the business process management and organization development approaches explain how structures and processes can be adapted. The organization of manufacturing startup companies needs to be agile to adapt to the current situation on the one hand. On the other hand startup companies have different preconditions, such as limited resources. To handle the different preconditions the strategic organizational structures need to be changed. Therefore a guideline with the main levers for the organization configuration is needed. 


\section{Approach}

The presented approach includes the main lever process management, the organization of corporate structures and the organizational development.

As shown in Figure 2, there is an appropriate balance for process management within the organization. The value proposition of process control depends on the scope and detailing of the process control. During the growth of the company the appropriate balance of process control can be different, so that a continuous observation and adaption of the organization is needed.

The presented approaches of business process management can be placed on the right side of the graph in the context of Startup companies. As described above they represent important methods to reorganize business processes.

On the other hand approaches such as the Lean Startup theory are usually based on low scope of process control which can be placed on the left side of the graph in the context of Startup companies. These are useful methods for the product development which reach their limits in terms of business process management.



Fig. 2. Value proposition of process management (Source: Adapted from [4])

Turning points of the organization and its processes are so called business process instances [13]. In the original context business process instances are used to build business processes without any workflows. The aim of this paper is to put business process instances in a wider context to describe major changes in the organization, such as increase of employees or changing product requirements. At those turning points the existing organizational structures and the processes need to be reviewed if their value proposition is still at the appropriate balance. If a change is needed the three levers of process, organization and the strategy for growth should be taken into consideration to reconfigure the existing set-up.

The first lever represents the process standardization. Processes, which are predominantly focusing on the Process effectiveness, are reflected by flexible 
and creative processes, such as an agile product development. Process effectiveness is needed when starting the development of a new product. On the other hand predominantly process efficiency is shown through process standardization and itemization. Efficiency in the organization is needed to structure recurring processes. The trade-off is between process standardization or individual coordination.

The second lever is the form of organization between specialists and generalists. Specialization is given in a rigid organization when employees can focus on a special task. On the other hand generalists are employees working on different tasks which can be enabled through a flexible organization. The trade-off is given between differentiation and integration.

The third lever is the difference between fast growth and sustainability in the organization. Quick growth can be enabled through flat hierarchy as small teams stay agile and can take decisions quickly. Sustainability in the organization is the establishment of standards. The trade-off is between the a decentralized organization with decision-making authority in each department and a centralized organization.

\section{Case Study}

The approach will be investigated with an ongoing case study with a startup company. The method used to conduct the case study are semi-structured interviews to get information about the development of the startup company in regard to the changes within the processes and the organization.

The company is a startup company developing products for electromobility. The company was founded with around 30 people working in different departments such as the product development, prototyping production or even the purchasing. At the beginning each employee worked on a special task, mostly development tasks in agile development processes. There was only one hierarchy level to enable fast decision taking and each team could organize their work on their own. Information was mainly spread on inquiry via face-to-face communication as the employees were located close to each other. The communication system was based on short weekly meetings to keep each other informed about the current status of the projects. Processes were implemented step by step according to the needs of the company. At that time the appropriate balance of process control was found.

The startup company grew quickly within its first year by acquiring new employees. During the growth of this startup company the number of employees increased fast so that it wasn't possible to spread all information needed only on inquiry as important information got lost. This was the first business process instance. As shown in figure 3, the value of the existing process configuration was not the appropriate balance anymore but more detailing was needed. Therefore standard meetings and reporting structures for the different tasks in the organization were developed to keep each other informed. The processes were 
documented in a flexible interactive management system to be efficient in simple, reoccurring processes, such as the purchasing process.

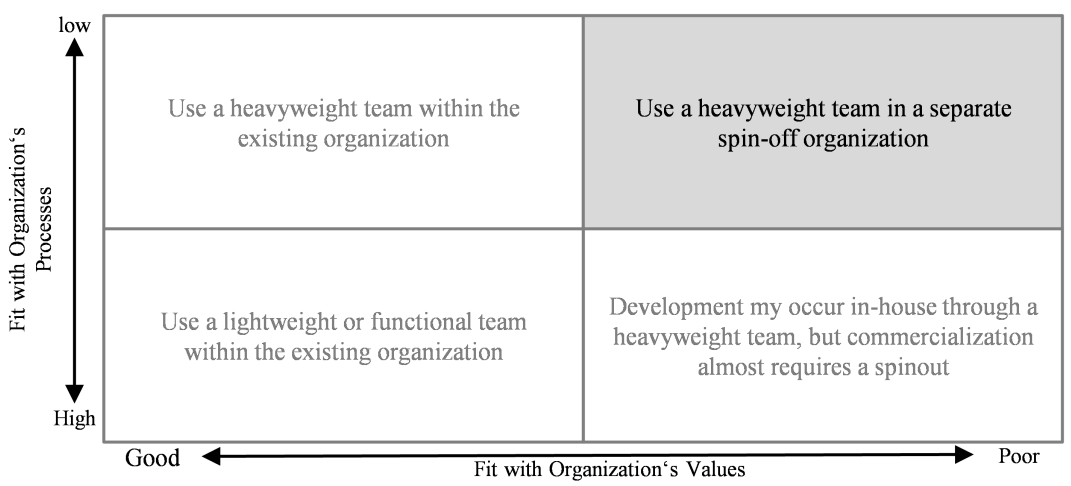

Fig. 3. Business process instances change value proposition of process management

The second business instance has been the progress in the product development. As the product was specified more and more the development speed slowed down with the existing organization structures. The value of process control was not at the appropriate balance any more as the existing structure of information meetings for the whole team was too much. Therefore the organization was transformed to small autonomous teams by using the portfolio work [12] approach. Each employee working in the purchase department was linked to one development team to do their purchasing tasks. Meetings were organized in smaller teams on special task and less meetings for all employees together.

The investigation will be continued to identify more business process instances and the needed changes for the processes, the organization and the strategy for growth.

\section{Conclusion}

In summary, there is a lack of finding the appropriate balance for the process and organization management of startup companies. Therefore the challenge is to create adaptive processes and organization structures. The presented approach is based on business process instances to identify needed changes within the organization and its processes. Further work needs to be done to detail and validate the presented approach. The main levers for the configuration can be detailed. In a second step the identified specific business process instances need to be transformed into generic business process instances. The third step is the description of the needed change configuration according to the business process instances. Overall a validation of the concept needs to be done to prove the 
presented approach. Therefore the method of semi-structured interviews will be conducted with more startup companies during their growths.

\section{Acknowledgement}

The authors would like to thank the German Research Foundation DFG for the kind support within the Cluster of Excellence "Integrative Production Technology for High-Wage Countries".

\section{References}

1. Christensen, C.M., Overdorf, M.: Meeting the Challenge of Disruptive Change. Harvard Business Review 78(2), 66-77 (2000)

2. Audi: http://www . audi.com/corporate/de/unternehmen/ unternehmensstruktur/audi-beteiligungen/audi-business-innovation.html

3. Agile Manifesto: http://agilemanifesto.org/iso/en/

4. Bergsmann, S.: End-to-End-Geschäftsprozessmanagement. Springer Science \& Business (2011)

5. Vom Brocke, J., Rosemann, M., et al.: Handbook on Business Process Management. Springer Verlag, Heidelberg (2015)

6. Harrington, H.J.: Business Process Improvement: The Breakthrough Strategy for Total Quality, productivity, and competitiveness. McGraw Hill, New York (1991)

7. Davenport, T.H.: Process Innovation: Reengineering Work Through Information Technology. Harvard Business Press, Boston (1993)

8. Hammer, M., Champy, J.: Reengineering the Corporation: Manifesto for Business Revolution. HarperBusiness (1993)

9. Chandler, A., Hagstrom, P., Solvell, O.: The Dynamic Firm: The Role of Technology, Strategy, Organization, and Regions. Oxford University Press (2003)

10. Behrens, C., Weßel, S.: Interaktive Prozessorientierte Managementsysteme. Dynamische und Stabile Prozesse im Unternehmen mit nachhaltiger Nutzung des Organisatorischen Wissens der Mitarbeiter. Industrie Management 30 (2014)

11. Lewin, K.: Field Theory in Social Science: Selected Theoretical Papers. Harpers Torchbooks, New York (1951)

12. Gross, P.: Jobholder-Value und Portfolio-Work: die Neuerfindung der Arbeit. Haupt, Bern (2000)

13. Rosa, M., Soffer, P.: Business Process Management Workshops. Springer Verlag, Berlin (2013) 